SHS Web of Conferences 17, 01005 (2015)

DOI: $10.1051 /$ shsconf $/ 20151701005$

(C) Owned by the authors, published by EDP Sciences, 2015

\title{
The Analysis of the Science and Technology Enterprise Core Employee Turnover Negative Effects - Based on the theory of psychological contract
}

\author{
Xin $\operatorname{Jin}^{1}$, Lijun $\mathrm{Li}^{2}$ \\ ${ }^{1}$ TianJin University of Science and Technology, 300222, Tianjin, China \\ ${ }^{2}$ Tianjin Wuqing Municipal People's Government, 301700, Tianjin, China
}

\begin{abstract}
This article explores the problem of negative effect of resignation of core employees from scientific enterprise based on psychological contract theory and summary of references. It uses questionnaires to analyze the data and construct a model of negative effect of resignation caused by psychological contract violation. It also makes an analysis on resignation tendency and negative effect of resignation in two perspectives to provide a basis for reduction of the negative effect.
\end{abstract}

Keywords. psychological contract; core employee; negative effect of resignation

Technological enterprise is an important primary force to improve national innovation ability and scientific level, and belongs to intelligence-intensive enterprise that produces high-tech products, so it has a high demand on talents, especially the ones that master professional knowledge and core technology. $20 \%$ of employees in technological enterprise master the core technology in the enterprise and are able to create $80 \%$ of values and profits for the enterprise. They are called core employees. The core employees have a dominant position in the enterprise. Their resignations will bring significant or even destructive negative effect on the technological enterprise. The core employees play an irreplaceable role in the technical development of technological enterprise, and they also have many special features in values and psychological demand- they are very independent and innovative, as well as have a strong demand on self-realization and focus on achievement. Therefore, their relation with the enterprise is distinguished from that of other traditional enterprises with their employees. The enterprise cannot restrain them only by existing employment contract but paying more attention to their satisfaction with psychological contract.

\section{Overview of psychological contract theory}

Argyris first used "psychological working contract" to describe the relation between the employer and employee. In his masterpiece Humanity and Organization: Conflict between System and Individual, he proposed an assumption "personality and organization" and established a framework indicating the difference of healthy individual demand and formal organization requirement ${ }^{[1]}$. While Argyris did not give a clear definition about this concept. Based on the research of Argyris, Levison developed a detailed theory. He made researches and proposed the psychological contract was defined as a concept describing the mutual expectation between 
employee and organization ${ }^{[2]}$. This is an internal expectation not explicitly expressed. This concept highlights the relation of mutual expectation not explicitly expressed apart from the formal contract or other material documents signed between employer and employee. Schein thought the psychological contract was an "integration of individual contribution, obtention of organization desire and the individual expectation provided by organization". (1) Roussseau thought the psychological contract should be formally defined as the fact "the individual employee and organization both trust that the other party will comply with the content specified between them and implement the due obligation". (2)

In all, the current psychological contract has two understandings respectively in broad and narrow sense based on the analysis of concept. The psychological contract in broad sense refers to the subjective understanding of organization and employee about the mutual responsibility and obligation in the employment relation. The psychological contract in narrow sense refers to various believes of responsibility and obligation formed between employee and organization based on their relation, as well as on promise and sensation. This article conducts a research in perspective of employee in technological enterprise, so it is suitable to use the concept in narrow sense.

According to the analysis on content and structure, there are mainly two ideas in the research about psychological contract, respectively 2D structure theory and 3D structure theory. MacNeil thought the contract relation included two dimensions, namely relation and transaction. He's also an initiator of 2D structure theory. Based on research result from MacNeil, Rousseau and Tijorimala added a team member dimension and proposed 3D structure theory for psychological contract, including relation, transaction and team member dimension ${ }^{[3]}$. Chinese scholar Yuan Li proposed a $3 \mathrm{D}$ structure theory for psychological contract suitable for Chinese employees. He thought the psychological contract included interpersonal, standard and development dimension ${ }^{[4]}$.

Generated in the interaction between employee and organization, the psychological contract mainly reflects a psychological expectation between the employee and enterprise. If the psychological expectation fails to be performed or realized to a certain extent in the interaction, it will induce another psychological contract problem_— psychological contract violation.

\section{Relation of psychological contract violation and employee resignation}

If the employee thinks the organization does not make proper response though he has made contribution or fulfill his due responsibility to the organization, the employee will feel like having an unfair treatment and his psychological demand is not satisfied. When this kind of demand is not met, the passive psychological experience of the employee will severely weaken the mutual psychological contract relation, and further induce the psychological contract violation.

There are many scholars making researches on the relation between psychological contract violation and resignation. Robinson, Kratz and Rousseau thought the psychological contract violation caused decline in enterprise performance and increase of resignation rate. Kickul, Lester and Finkl found from their research that the psychological contract violation of employee had a positive correlation with the resignation tendency ${ }^{[6]}$. From the research on the impact of psychological contract violation on the attitude and behavior of employee in the enterprise, Ying $\mathrm{Yu}$ (2010) found that: the psychological contract violation had an obvious negative correlation with working performance, working satisfaction and research tendency.

Robinson and Rousseau further summarized those researches and concluded the psychological contract violation will induce "EVLN" behavior for employee, namely Exit, Voice, Loyalty and Neglect, among which the Exit is the most serious problem caused by psychological contract violation. However, compared to general employee, the core employee in the enterprise has a higher value superiority, psychological expectation, independence and liquidity, so it is more possible for them to reduce the working performance, sense of responsibility and decrease the trust 
and loyalty to the enterprise instead of keeping silent or being tolerant like the general employees if that psychological contract they attach much importance to is not satisfied.

Considering all the relevant research results, we may conclude the psychological contract violation will not necessarily induce resignation of employee but producing a thought to leave the organization, namely the resignation tendency. They are presented as obvious positive correlation. The constantly intensified psychological contract violation will cause employee's resignation (as shown in Figure 1). We can say the psychological contract violation is an important factor that causes the generation of employee's resignation tendency and their final resignation behavior.

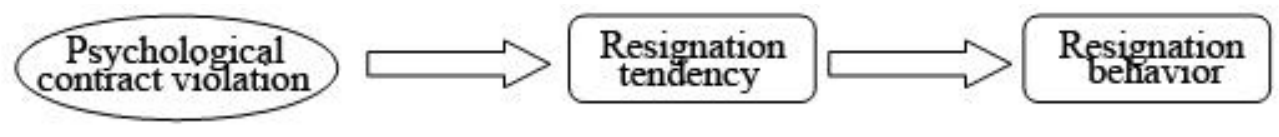

Figure 1. Process where the psychological contract violation causes resignation

\section{Research on impact mode of negative effect of resignation}

There are many scholars making researches on how the psychological contract violation influences resignation tendency of employee and what consequence will be induced in this influencing course, but few of them have made further study, and most of the researches were based on all the employees, which means there is a lack of research conducted for clearly classified enterprises and a certain group of employees. For that reason, this article takes the core employee in the technological enterprise as the research objective, and makes detailed analysis on negative effect of resignation of core employee in the technological enterprise by questionnaire and data analysis. It also tries to show the detailed representation of negative effect of resignation of core employee from the technological enterprise in a more direct manner by constructing a conceptual model of negative effect of resignation of core employee from the technological enterprise.

\subsection{Research design}

\subsubsection{Questionnaire design}

This article designs a questionnaire scale for core employee in technological enterprise based on relevant research scales of the same kind. The questionnaire is named Questionnaire about Negative Effect of Resignation of Core Employee, divided into four parts: The first part is used to fill in some basic information about the investigated objective; The second part collects the information about the actual conditions of employee in the position of senior management (including the employee in senior or higher rank of technology), including the resignation experience and comparison of enterprise nature between the original and current enterprise; The third part collects the information about the impact of resignation of the colleagues around the investigated objective who are in key posts and management layer on the investigated objective, including the impact of resignation tendency on working employees and the other ones. Each item in this part uses Likert 5-level scale method, namely completely compliant, fairly compliant, not sure, non-compliant, completely non-compliant; The fourth part shall be filled by senior management in technical department and is used to investigate the impact of resignation tendency of general and core employees on the enterprise.

This questionnaire mainly includes the investigation on the negative effect of resignation tendency and behavior of core employees in technological enterprise on the employees themselves and the enterprise. The questions were unknown to belong to which part of the questionnaire when it released, and the questionnaire was filled anonymously, because in this way, the respondents 
would fill the questionnaire more objective, and on the other hand, it ensured the truth and reliability of the questionnaire.

\subsubsection{Sample selection}

According to the opinion of Zhen Wang, et al., "the core employee is defined according to a certain development stage of a certain industry and enterprise, that is to say, the definition of core employee in different development stage of different industries, enterprises or the same enterprise is varied", this article defines the core employee of technological enterprise mainly involved in technical research and development as "talents of technical research and development who have professional skills to form the core competitiveness for enterprise, who are in the key posts of enterprise and who have high scarcity of human resources", so the objectives the questionnaires were mainly released to were the employees of technical research and development department in technological enterprise. There were totally 300 questionnaires released through Email, QQ, Wechat and personal delivery, with 272 returned, rate of return 90.6\%. All the returned questionnaires are valid.

\subsection{Analysis on negative effect of resignation tendency of core employees from technological enterprise}

Sager and other scholars proposed that resignation tendency is the best variable to predict the resignation. Mobley thought the employee will expect for resignation after he experiences discontent, but the resignation tendency is generated after resignation expectation, working opportunity seeking and other steps, and it's the final step before the actual resignation. Currently, there are many researches on resignation tendency, but most of them study the causes of resignation tendency instead of the impact it imposes. Jinbo $\mathrm{Li}$, et al. found from empirical research that resignation tendency imposes a significant adverse impact on individual working performance, and further on the overall performance of the enterprise ${ }^{[9]}$. So this article thinks the increase of employee's resignation tendency will also induce a series of adverse impacts even if there's no actual resignation, and the resignation tendency of core employees in technological enterprise is especially significant.

The negative effect of resignation tendency of core employees in technological enterprise is imposed on two things, namely on enterprise and the other employees.

(1) Negative effect on enterprise_-low working enthusiasm

The relevant data in the questionnaire obtained from investigation on senior management shows that $22 \%$ of senior managements found the core employees had a reduced working enthusiasm and passive working attitude after generation of resignation tendency and before the generation of resignation behavior. It is mainly because the resignation tendency causes the work seeking behavior of core employees. They will invest more in seeking works, thus less in the internal jobs of the enterprise, which will reduce their working enthusiasm, cause passive working attitude and lower the working efficiency.

But fortunately, $40 \%$ of senior executives found "the working was not affected much though the working enthusiasm of core employees reduced" before resignation; In addition, $35 \%$ of the senior executives thought the "working attitude of core employees was not changed" before resignation; $3 \%$ of senior executives thought "the working enthusiasm of core employees was conversely increased and they worked really hard". This is mainly because most of the core employees have accepted higher education, so they have a good professional ethics and integrity. They won't take the energy limitation as an excuse for not working hard; Furthermore, the core employees generally will find a job before resignation, and this may reduce much of their psychological burden. So they can "do well in the final work".

(2) Negative effect on the other employees_-generating passive emotion 
The situation described in the third part of questionnaire ("I feel low and frustrated when hearing that he/she may resign") tries to find out whether the resignation tendency of core employees will influence the emotion of other employees. 272 of the investigated objectives selected the relevant options according to their own feelings. Among them, there were 14(accounting for 5\%) selecting "completely compliant" and 107(accounting for 39\%) selecting "fairly compliant". The number of employees selecting "non-compliant" and "completely noncompliant" was respectively 87 (accounting for 32\%) and 4 (accounting for $2 \%$ ), and there were 60 (accounting for $22 \%$ ) employees selecting "not sure". In all, there were over 40 percentages (44\%) of investigated objectives that would have a passive emotion to a certain extent due to resignation tendency of the core employees in their daily work.

The core employees are either in the key posts of technological enterprise or have a great influence on others so that their working strategy and way of act becomes an example and benchmark for the other employees, and even a little movement will affect their subordinates or direct cooperators. When knowing the resignation attempt of the core employees, the other employees will probably generate passive emotion and passive attitude to work. So the resignation tendency of core employees will easily induce concern, anxiety, worry and other passive emotions for the other employees, and thus affect the normal implementation of work. For a part of employees on good terms with the core employees that have resignation tendency, the passive emotion will be amplified.

\subsection{Research on negative effect of resignation of core employees from technological enterprise}

The domestic and foreign scholars have made relevant researches on the impact of employee's resignation behavior Katz made a research and pointed that the excessive liquidity of employees will reduce the overall beneficial result of enterprise. Glebbeek and Bax found from research that the liquidity rate of employee is in " $\cap$ " relation with enterprise performance ${ }^{[10]}$. Some domestic scholars focus on the liquid costs of employees, for example, Shuming Zhao and Dejun Cheng pointed that the reduced employee liquidity rate can decrease the costs of, such as employment and training, for the enterprise ${ }^{[11]}$; Found from a research on the impact of employee liquidity on the enterprise performance, Youli Huang and Ming Hua pointed that the liquidity rate of employee is in positive correlation with the liquidity costs of employee. Furthermore, high liquidity rate of employee will jeopardize the continuity of knowledge in the organization ${ }^{[12]}$. Hongzhen Lei and $\mathrm{Yu}$ Jia thought the group resignation causes loss of organization knowledge and thus increases risk for enterprise ${ }^{[13]}$. Some other scholars made an analysis based on the impact of employee resignation on their psychology. For example, from a research on current situation of scientific talents loss, Yu Wang, et al. pointed that the loss of human resources induce psychological fluctuation for the other employees and reduce the morale ${ }^{[14]}$; Chunhui Lou also thought the resignation of enterprise employee will have an adverse impact on the insensible employees.

By summarizing the current references and considering the features of core employees in the technological enterprise, this article thinks the negative effect of resignation of core employees in technological enterprise, similar to negative effect of resignation tendency, is reflected in two aspects, namely the effect on enterprise and on working employees.

(1) Negative effect on enterprise

A. Costs increase

As shown in the investigated data of the fourth part of the questionnaire, when the core employees resign, $44 \%$ of the senior executives found the new successors generally would just hurriedly and simply took over the job of the resigned core employees; $30 \%$ selected the option "the new employees can be found for takeover only sometime after the resignation of core employees"; $3 \%$ found the posts left by resigned core employees are still vacant; $47 \%$ thought, as for the question "whether the new successor can completely take over the technical ability of the resigned core employees", the successors must be trained for some time before achieving the 
technical level of resigned core employees, which was agreed by a considerable proportion of senior executives.

The above data indicates the resignation of core employees will increase the costs of enterprise, mainly including the costs of employment and training. The costs of employment refer to the relevant expenses induced by the fact that a new employee takes over the post of resigned one. The regular employee can be recruited in regular job fair and on the Internet, and the required costs are relatively low; while the expenditure for recruiting the core employees is considerable, because the high-level talents are required to be employed by professional employment agents. However, the relevant expenses for precious talents in special period or with special skills will be very large. The training costs refer to various costs of professional training for the new employees before officially working in the enterprise. And the costs for training a core employee are far more than that for general employees. But the previous investment of enterprise in the core employees will never return with their resignation. The new employees requires a long time before completely taking over the core employees, and in this course, the company needs to provide more resources and environment.

B. Business prevention

According to their previous actual conditions, the investigated senior executives made options about the investigation of the impact of core employee resignation on the project or business, and $15 \%$ of the respondents found "the project or business will take a long time for recovery" and $2 \%$ selected "the project or business remains unenforceable", $50 \%$ of senior executives selecting "the project or business is recovered fast". According to the data above, nearly two thirds $(67 \%)$ of investigated objectives found there's still some impact of core employee resignation on the project or business.

As a rare resource in the job market, the core employees have a wide range of jobs to choose and are able to get a new employment opportunity fast, so their resignation may be sudden. In the market environment with intense competition, the resignation of core employees in enterprise will definitely induce loss of business continuity. The enterprises with rigorous organizational continuous and strong overall strength can minimize the loss by post transfer and staff complementation. While for part of the enterprises, the possible failure to take efficient countermeasures may cause business interruption.

C. Knowledge loss

As shown in the questionnaire, totally $37 \%$ of senior executives thought the knowledge loss induced by core employee resignation will have an impact on the organization; $32 \%$ selected the option that "the core employee resignation causes a part of knowledge loss which has a certain impact on the organization"; $5 \%$ selected the option that "the loss of core knowledge will have an irreversible impact on the organization"; $35 \%$ thought the core knowledge is not taken by the core employee and is left in the organization.

For a technological enterprise, the core employee who has the key knowledge and core technology is considered as an important immaterial asset, and in some way, they can be more important than the material assets. The documents, drawings, programs, technical documents and other explicit data generated from the working of core employees may be well kept, but the more important management mentality, professional skills, working experience and other implicit knowledge summarized in practice are rooted in their minds which cannot be fully copied or transferred. Resignation of these employees implies a complete loss of valuable knowledge resources accumulated in the enterprise.

D. External competition intensified

As for where the core employees will go after resignation, $44 \%$ of investigated objectives selected the option that they will enter a competitive enterprise to work; $23 \%$ found the core employees have entered a cooperative enterprise to work.

With highly specialized skills, the core employees tend to continue their careers in a certain professional field. It means the new career of those core employees will be probably started in a direct or indirect competitor of the original company, which has been justified by the above 
investigation results. What the core employees have taken to the competitor includes not only the knowledge resources and core competitiveness of the enterprise, but also, in a worse case, the key client resources and core technologies. It will greatly change the external environment that the enterprise faces.

(2) Negative effect on working employees

A. Heavier workload

The relevant items in the third part of questionnaire ("my workload becomes heavier sometime after his/her resignation") aim at getting to know whether the resignation of core employees will make the workload of working employees heavier. There were respectively 39 and 93 people selecting "completely compliant" and "fairly compliant", indicating the workload of investigated objectives, the number of whom is nearly half (48\%) of investigated sample proportion, was obviously made heavier directly from the resignation of core employees.

There's little time for core employees to go from having resignation tendency to actual resignation, so their resignation will "suddenly happen"_—which easily cause work stoppage, and it's difficult for the original enterprise to seek their successors. Therefore, before discovering a proper successor, the enterprise tends to assign the important work of resigned worker to the others at work. While for the employees in the department of research and development in a technological enterprise, they may be incapable of undertaking the overload from work as the routine work for them is already saturated and full of challenges.

B. Forced to change post

According to data statistics from relevant items in the third part of questionnaire ("it is annoying that his/her resignation forces me to change my duty and scope of work"), it indicates that a certain proportion $(21 \%)$ of employees in the post of technical research and development had experienced the situation where they were forced to change their posts due to resignation of core employees, which had made them upset.

The post in the department of research and development in a technological enterprise is generally set according to the actual working requirement and working tasks of the enterprise. The project or task will be easily aborted or changed if the enterprise does not properly deal with the resignation of core employee, and this will further change the duty and scope of work in some posts, making some working employees forced to leave original posts and give up their familiar working content.

C. Generating passive emotion

According to data statistics of relevant items in the questionnaire ("His/her resignation makes me somewhat anxious"), it is found, of 272 employees involved in the technical research and development, there were 120 (44\%) thinking the resignation of core employee has an impact on their working emotions, mainly represented by passive emotion and working attitude.

As a model and backbone of team for the employees, the core employee, when having the resignation tendency, will bring passive emotion for the rest members, and it will persist for a certain period after the resignation of core employee. As the core employee formally resigns, the other employees will have a strong psychological impact that causes slack feelings for employees in the enterprise, and further weaken and influence the enterprise cohesiveness and employee's morale. The resignation of some core employees with large influence will even induce group psychological unrest, weaken the concentric force and cohesiveness, undermine the employee's confidence to the enterprise and greatly jeopardize the overall morale for the whole team.

D. Generating resignation tendency

The resignation of core employee will have a indirect impact on the working and psychological factors of working employees, and directly provide power for them to have a thought of resignation in the form of external behavior.

The relevant data from questionnaire investigation shows that $26 \%$ (71 people) of the investigated objectives said they got a lot of employment information from core employees; $21 \%$ (59 people) said the core employees of the enterprise used to suggest them to leave the enterprise, for which $16 \%$ (45 people) used to have a thought of resignation. 
The constant development of passive emotion in the other employees due to the resignation of core employees will influence their stability and loyalty to enterprise. Especially when other employees find the core employees had got a better development opportunity or more profits after resignation, they will also consider their own situation, which may reduce their royalty to the enterprise and thus generate the thought of resignation. In addition, it will influence many working employees and easily induce a wide range of resignation tendency, which influences the group stability and cause group resignation. It may become a destructive hit on a technological enterprise with all efforts in the independent innovation ability and core talents team.

\section{Concept model of negative effect of resignation of core employee}

According to the above analysis, this article constructs a concept model of negative effect of resignation caused by psychological contract violation, as shown in Figure 2:

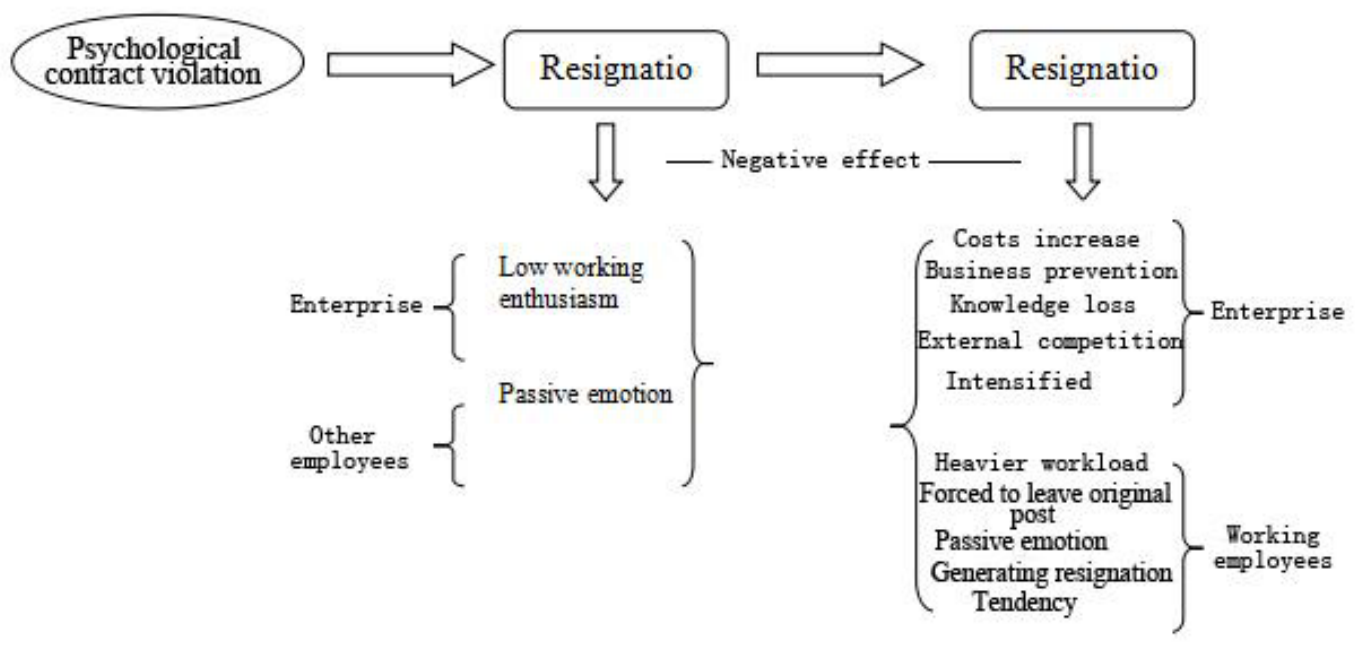

Figure 2. Concept model of negative effect of resignation caused by psychological contract violation

After psychological contract violation, the core employee in technological enterprise will first have the resignation tendency. As the resignation tendency is constantly intensified, it will induce the actual resignation of core employees. In the whole process of resignation, the core employees have a series of absolutely adverse impacts on the enterprise and other employees, so those impacts are defined as "negative impacts".

The negative effect of resignation tendency of core employee is mainly reflected in the enterprise and other employees, among which the negative effect on the enterprise is mainly reflected as "low working enthusiasm"; the effect on the other employees as the response of emotion that produces "passive emotion" in them.

As the core employees actually resigned from enterprise, the negative effect thereon is mainly reflected in the following aspects: 1. causing "costs increase"; 2. inducing "business prevention" such as sudden interruption of business or failure to timely complete the business; 3 . causing "knowledge loss" as the core employee takes away the implicit and explicit knowledge after resignation; 4. inducing "external competition intensified" situation for original enterprise as the core employee enters a competitor's company after resignation. The resignation of core employee also has a negative effect on working employees, mainly reflected as follows: the sudden resignation of core employee causes "heavier workload" for the other employees; the working employee is "forced to leave the original post" due to interruption of company project or business, 
making them have "passive emotion"; what's worse, it may also induce the "resignation tendency" among the working employees.

\section{References}

1. Algyris, C. Understanding Organizational Behavior [M]. London: Tavisroek Publications, 1957: 29-51.

2. Levinson. Organizational Diagnosis [M]. Harvard University Press, 1972: 7-13.

3. Rousseau, D.M., Tijoriwala. Perceived Legitimacy \& Unilateral Contract Changes: It Takes A Good Reason To Change A Psychological Contract [A]. San Diago, 1996.

4. Li, Y. Research on the Structure and Relevant Factors of Employee's Psychological Contract [D]. Beijing: Capital Normal University, 2002

5. Robinson, S.L., Morrison, W. Psychological Contracts and Ocb: The Effect of Unfulfilled Obligations on Civic Virtue Behavior [J]. Journal of Organizational Behavior, 1995, 16(3): 289-298.

6. Kickul J., Lester S.W., Finkl J. Promise Breaking During Radical Organizational Change: Do Justice Interventions Make a Difference [J]. Journal of Organizational Behavior, 2002, 23: 469-488.

7. Robinson, S.L. , Kraatz, M. , Rousseau, D. M. Changing Obligations and the Psychological Contract: A Longitudinal Study [J]. Academy of Management Journal, 1994, 37(1): 137-152.

8. Mobley, W. H. Intermediate Linkage in the Relationship between Job Satisfaction and Employee Turnover [J]. Journal of Applied Psychology, 1977(62): 237-240.

9. Li, J.B., Xu, B.H., Zhang, Y.Y. Research on the Impact of Organization Commitment on Employee's Behavior and Working Performance [J]. Ergonomics, 2006, 12(9): 17-19.

10. Jin, J.X. Research on Resignation of Knowledge-type Employee and Its Impact on Enterprise Performance [D]. Shanghai: Traffic University Of East China, 2007.

11. Cheng, D.J., Zhao S.M. Participation in Working System and Enterprise Performance: Impact of Human Resource Capital Specificity and Environment Dynamics [J]. Management World, 2006(3): 86-93.

12. Huang, Y.L., Hua, M. Discussion on Strategic Human Resources Management and Organization Performance Issue [J]. Chinese Human Resources Development, 2004(3): 25-27.

13. Lei, H.Z., Jia, Y. Discussion on Loss of Organization Knowledge Due to Employee's Resignation--based on the perspective of group resignation [J]. Soft Science, 2010, 24(9): 115-119.

14. Wang, Y., Shi, S. Current Situation of Loss of Technical Talents in High-tech Enterprise and Its Countermeasure [J]. Technology and Innovation Management, 2006, 27(3): 66-68.

15. Lou, C.H. Mode of Voluntary Resignation Costs for Enterprise Employees and Its Management Measures [J]. Chinese Human Resources Development, 2004(6): 47-49. 